\title{
NASA's Kilopower Reactor Development and the Path to Higher Power Missions
}

\author{
Marc A. Gibson; Steven R. Oleson \\ NASA Glenn Research Center \\ 21000 Brookpark Rd. \\ Clevelend, OH 44135 \\ (216) 433-5562; (216) 789-2026 \\ marc.a.gibson@nasa.gov \\ steven.r.oleson@nasa.gov
}

\author{
David I. Poston; Patrick McClure \\ Los Alamos National Lab \\ P.O. Box 1163, MS C-951, \\ Los Alamos, NM 87545 \\ (505) 667-4336; (505) 667-9534 \\ poston@lanl.gov \\ pmcclure@lanl.gov
}

\begin{abstract}
The development of NASA's Kilopower fission reactor is taking large strides toward flight development with several successful tests completed during its technology demonstration trials. The Kilopower reactors are designed to provide 1-10 $\mathrm{kW}$ of electrical power to a spacecraft or lander, which could be used for additional science instruments, the ability to power electric propulsion systems, or support human exploration on another planet. Power rich nuclear missions have been excluded from NASA mission proposals because of the lack of radioisotope fuel and the absence of a flight qualified fission system. NASA has partnered with the Department of Energy's National Nuclear Security Administration to develop the Kilopower reactor using existing facilities and infrastructure and determine if the reactor design is suitable for flight development. The threeyear Kilopower project started in 2015 with a challenging goal of building and testing a full-scale flight-prototypic nuclear reactor by the end of 2017 . Initially, the power system will undergo several non-nuclear tests using an electrical heat source and a depleted uranium core to verify the complete nonnuclear system design prior to any nuclear testing. After successful completion of the depleted uranium test, the system will be shipped to the Nevada National Security Site where it will be fueled with the highly enriched uranium core and retested using the nuclear heat source. At completion of the project, NASA will have a significant sum of experimental data with a flight-prototypic fission power system, greatly reducing the technical and programmatic risks associated with further flight development. To compliment the hardware rich development progress, a review of several higher power mission studies are included to emphasize the impact of having a flight qualified fission reactor. The studies cover several science missions that offer nuclear electric propulsion with the reactor supplying power to the spacecraft's propulsion system and the science instruments, enabling a new class of outer planet missions. A solar versus nuclear trade for Mars surface power is also reviewed to compare the advantages of each system in support of ascent vehicle propellant production and human expeditions. These mission studies offer insight into some of the benefits that fission power has to offer but still lacks a wider audience of influence. For example, mission directorates won't include a fission power system in their solicitations until it's flight qualified, and scientists won't propose new missions that require more power than what's currently proven and available. An attempt to break this chicken and egg effect has been ongoing with the Kilopower project with the goal of advancing the technology to a level that encourages a flight development program and allows scientists to propose new ideas for higher power missions.
\end{abstract}

\section{TABLE OF CONTENTS}

1. INTRODUCTION...............................................................1

2. DEVELOPMENT PROGRESS ....................................1

4. DEPLETED URANIUM SYSTEM TEST ........................3

5. NUCLEAR GROUND TESTING ..............................4

6. SCIENCE MISSIONS................................................5

7. HUMAN EXPLORATION MISSIONS............................8

8. SUMMARY ............................................................10

REFERENCES ….....................................................12

BIOGRAPHY …..................................................................12

\section{INTRODUCTION}

The U.S. space nuclear program has found considerable challenges in developing a flight qualified fission reactor for NASA missions over the past half century. In fact, the 1960's SNAP (Space Nuclear Auxiliary Power) program was not only the last time the U.S. has flown a space reactor, the 1965 launch of SNAP 10A, but is also the last time that the U.S. has completed a nuclear powered ground test for any space reactor. Without speculation, it is clear that a successful program will need to have clear advantages over current technologies, be affordable, and be efficiently executed by a qualified team. NASA has partnered with the Department of Energy's National Nuclear Security Administration to recruit specific talents in reactor design, fuel manufacturing, and criticality testing from the Los Alamos National Laboratory (LANL), the Y-12 National Security Complex and the Nevada National Security Site. This Kilopower team will hopefully overcome the historical challenges and successfully complete a nuclear ground test in 2017 that will provide crucial information about the reactor neutronics and verify if the design can power the future of space exploration.

\section{Development Progress}

\section{Early Developments}

After completion of the 2012 DUFF experiment $[3,10]$, the Kilopower team has been focused on the full-scale nuclear demonstration of the $1 \mathrm{kWe}$ fission power system. NASA's Space Technology Mission Directorate officially started the 
Kilopower project in 2015 with the goal of maturing the fission reactor technology to TRL5 by 2017. In order to complete the goal, the reactor is required to achieve steady state operation at the nominal core design temperature and power of $800 \mathrm{C}$ and $4 \mathrm{kWt}$ respectively within a space vacuum environment. Designing the reactor to reach these conditions requires extensive neutronic analysis that is heavily driven by material properties and design geometries. Additionally, the nuclear materials need to be readily available and in production within the DOE and commercial complexes. Taking these facts into account, and given the budget and schedule constraints, the Kilopower configuration was established in early 2015 during the conceptual design review. Early flight design concepts can be viewed in Figure 1.

\section{Material and Component Level Testing}

Throughout 2015, several material tests were initiated to understand certain properties that were either unavailable or were considered to be inconclusive based on past research data. Some of these tests included creep properties of the fuel, coefficient of thermal expansion of the fuel, and diffusion properties between the fuel and sodium heat pipes. In parallel with the material testing, subcomponent tests were initiated at NASA GRC to verify that the sodium heat pipes, as well as their connection to the reactor core, would
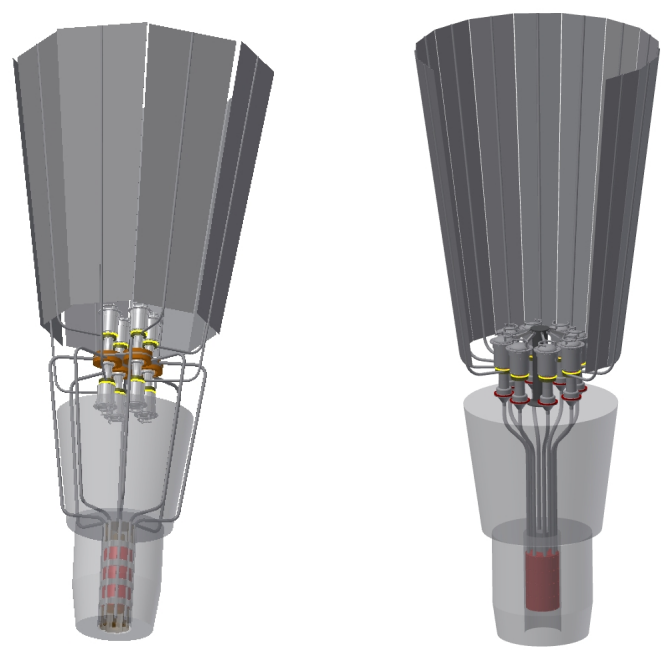

Figure 1. Kilopower 1kWe Fight Concepts: Left, baseline dual opposed configuration with sodium heat pipes assembled around the shield; Right, single engine configuration with sodium heat pipes passing through the shield.

sufficiently transfer heat from the reactor core to the power conversion system. Full-scale thermal prototype tests were conducted to study these effects using a stainless steel electrically heated surrogate core section. Figure 2 shows a picture of the thermal prototype testing conducted in 2015 with the sodium heat pipes transporting approximately $4 \mathrm{~kW}$ of thermal energy over a distance of $1 \mathrm{~m}$ from the evaporator, attached to the reactor core, to the condenser, radiating to the vacuum chamber.

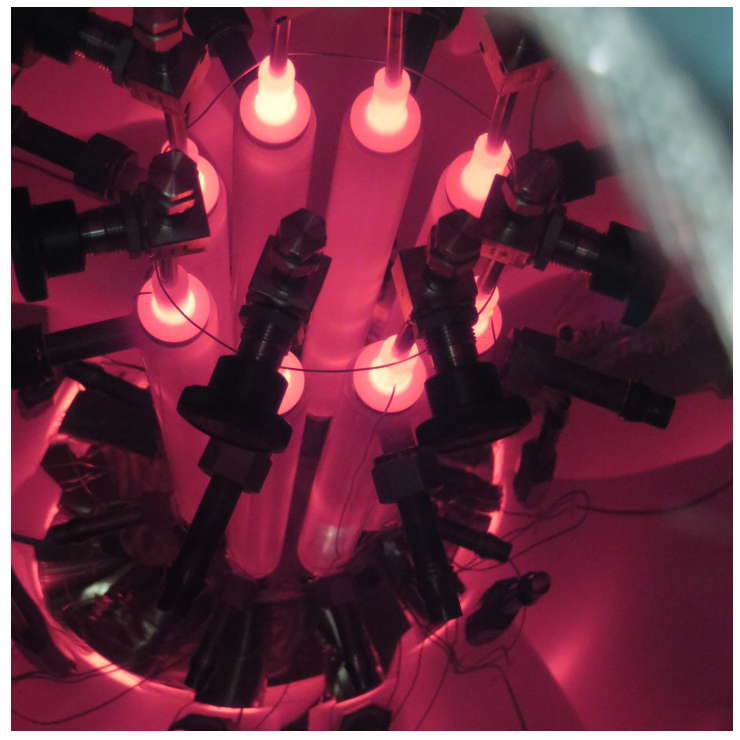

Figure 2. Thermal prototype testing with sodium heat pipes radiating at over $800 \mathrm{C}$ to the vacuum chamber walls as seen through the chamber view port.

\section{System Level Testing}

In 2016, major efforts were focused on completing the necessary non-nuclear system level tests at NASA GRC's VF71 facility to fully characterize the performance between the core and the thermal energy conversion process. These tests incorporated the surrogate stainless steel core, Haynes 230 sodium heat pipes, and Stirling power conversion. Several power conversion concepts were evaluated and ultimately led to two Stirling convertor designs that moderately differed in their configuration. Both configurations base-lined a total of eight $125 \mathrm{~W}$ Stirling convertors that would produce the required total electrical output of 1000 Watts to the spacecraft bus. Funding was not available to purchase new convertors so compromises were made to incorporate two of the existing $70 \mathrm{~W}$ convertors repurposed from the Advanced Stirling Radioisotope Generator (ASRG) project. With only two convertors, a Stirling thermal simulator was designed and fabricated to replace the remaining six convertor slots and balance the thermal load. The baseline design consisted of what is typically referred to as a dual convertor design in which the Stirling convertors are positioned opposing each other with the hot ends together. This allows the inertia forces from each convertor to be balanced through synchronous motion control. The second arrangement positioned all convertors, or thermal simulators, singularly, with the hot ends facing toward the reactor core. This configuration requires an active balancer connected to the backside of the convertor to balance the inertia forces from the moving convertor parts. The dual opposed baseline architecture can be seen in figure 3. 


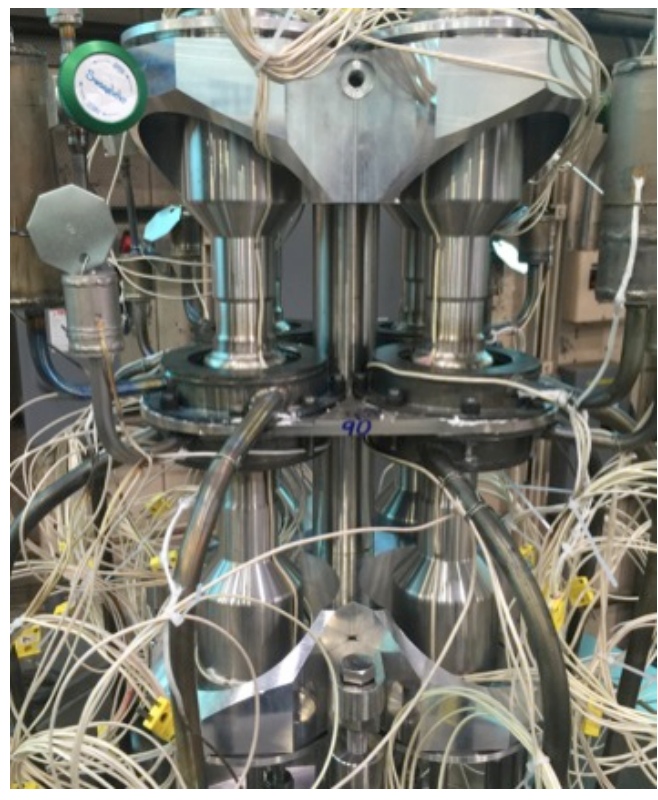

Figure 3. Balance of Plant hardware showing 8 sodium heat pipes attached to a conduction plate that supplies heat to 2 Stirling engines and 6 Stirling thermal simulators.

\section{Reactor Fueling}

One of the major design considerations of the Kilopower reactors is the fueling process at the launch site. Use of highly enriched uranium fuel requires increased levels of security, which have considerable costs. Integration between the reactor, spacecraft, and launch vehicle have direct impacts on the time required to fuel the reactor and complete payload assembly. At this point in the development process, the only task that can be addressed is the fueling process of the power system as the spacecraft and launch vehicle are unknown at this time. Flight integration of the reactor will always position the reactor core and shield opposing the spacecraft to allow the shield to protect the spacecraft as designed. This allows the unfueled power system to be available at the far end of the total payload. In this architecture, the payload integration could be designed in a way that the reactor fueling could be one of the final steps in the assembly test and launch operations process. This would allow the Highly Enriched Uranium (HEU) fuel to be shipped to the launch processing facility close to the launch date and thus decreasing the number of days that the fuel would need to be secured.

The fueling process of a Kilopower flight system would start at the bottom of the shield with access to the heat pipe evaporators. The radial reflector assembly and control rod would be detached during fueling. The assembly tooling would attach to the lower shield plate and align the centerlines of the power system and core. The flight shield could not be included into the nuclear ground test due to geometric constraints within the criticality test cell, so the lower portion of the vacuum chamber service collar is used for the tooling fixture base. Several surrogate fuel assemblies were completed at NASA GRC during the development process and provided time durations for the process. It was determined that the reactor could be fueled, instrumented, insulated, and canned within 12 hours. Additional time is required for assembling the control rod and radial reflector assembly, which is estimated to take an additional $8 \mathrm{hrs}$. A conservative estimate for the complete fueling process and reactor final assembly is determined to take no more than 4 working days. Figure 4 depicts the fuel assembly tooling and several ring clamps holding the heat pipes to the fuel.

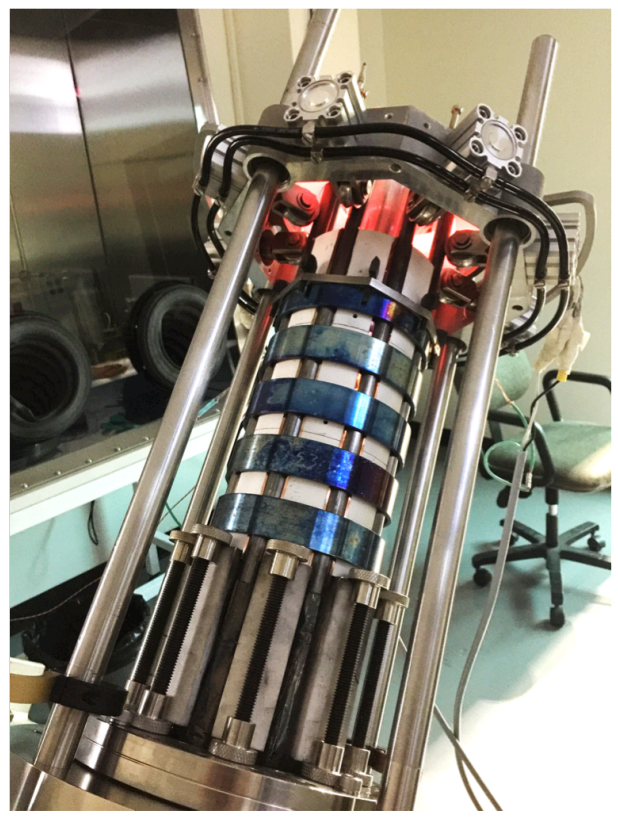

Figure 4. Reactor fueling: The final ring clamp being heated to $800 \mathrm{C}$ before being inserted around the heat pipes and core.

\section{DePleted UraniUm System Test}

\section{DU Risk Reduction}

The final risk reduction effort before conducting the nuclear testing was an electrically heated system test using a Depleted Uranium (DU) core. This core was fabricated by Y-12 and provided them the opportunity to develop their fabrication processes in preparation for the HEU core needed for the 2017 nuclear testing. The DU core is exactly the same material as the HEU core with the major difference being the depletion of the 235 isotope. The DU core allowed the research team to evaluate the mechanical and material interfaces to the Haynes 230 heat pipes as well as any differences in thermal performance.

The DU material also provided a unique opportunity for the Kilopower team to perform training exercises regarding fueling the reactor. Team members from the Marshall Space 
Flight Center (MSFC), LANL, and the Device Assembly Facility (DAF) visited GRC to undertake the first KRUSTY (Kilopower Reactor Using Stirling TechnologY) dress rehearsal to perform the assembly process without the security and criticality requirements associated with the HEU material. This exercise allowed the processes to be evaluated and modified before moving into HEU operations at DAF for the KRUSTY test. The DU material is slightly radioactive and requires radiological work procedures for safe handling, making the training as close to the HEU process as possible. Anytime fissionable materials are being handled, criticality safety is a major concern to make absolutely sure that specific geometries and moderators cannot combine to make the material critical throughout the manufacturing, machining, and assembly processes. New designs, such as Kilopower, require additional efforts in criticality safety, and performing the procedures with DU ensures a well-prepared operation.

Once the power system was fueled with the DU core it underwent the KRUSTY specific test protocols per the nuclear experiment plan. This allowed the steady state and transient temperature and power data to be benchmarked with the prior stainless steel surrogate core system testing as well as the nuclear heated model predictions. This test marked the final key milestone required to progress into the nuclear test phase with the KRUSTY test.

\section{Nuclear Ground Testing}

\section{KRUSTY Testing}

All the preparations and testing are leading up to the long sought return of a real U.S. space nuclear program starting with KRUSTY. In the summer of 2017, the KRUSTY tests performed at the DAF will complete a number of key components to moving the Kilopower reactors toward further flight development.

\section{Cold Critical Testing}

Several zero power critical tests will be completed to compare and verify neutronic modeling parameters. These nuclear data points will provide fundamental information that will be used to re-assess model results prior to performing experiments at power. In addition, one goal of the experiment is to try and get "clean" physics data for various materials and components. This data will be useful to the physics community at large, will aid in future Kilopower reactor designs, and will provide confidence in proceeding with KRUSTY experiments at power. Zero power critical tests are performed for several configurations of the reactor in a step-wise fashion (by adding components) so as to characterize the entire system. Each zero power critical determines the k-eff of a delayed-supercritical system (the reactivity of the system) from the slope of power increase measured for that system.

\section{Low Temperature Testing}

Several tests will be run at low temperature prior to testing at high temperature. These runs will limit the excess reactivity in the system to less than $\$ 0.80$. Limiting the excess reactivity in the system to less than $\$ 0.80$ ensures the system is controlled by delayed neutrons and limits the temperature in the system. The first run will be a $\$ 0.15$ free run that inserts $\$ 0.15$ rapidly and with no operator interactions after the insertion. This test will allow the analyst to correlate neutron population measured in the experiment to power in the reactor. The $\$ 0.15$ test will be followed by a test of $\$ 0.30$ and a test of $\$ 0.60$ in excess reactivity. These tests will begin with a $\$ 0.15$ free run and continue with steady state power as the operator inserts reactivity in $\$ 0.02$ intervals until the desired amount of excess reactivity is inserted in the system. These tests will again be used to validate modeling of the system prior to testing at full operating temperature and power.
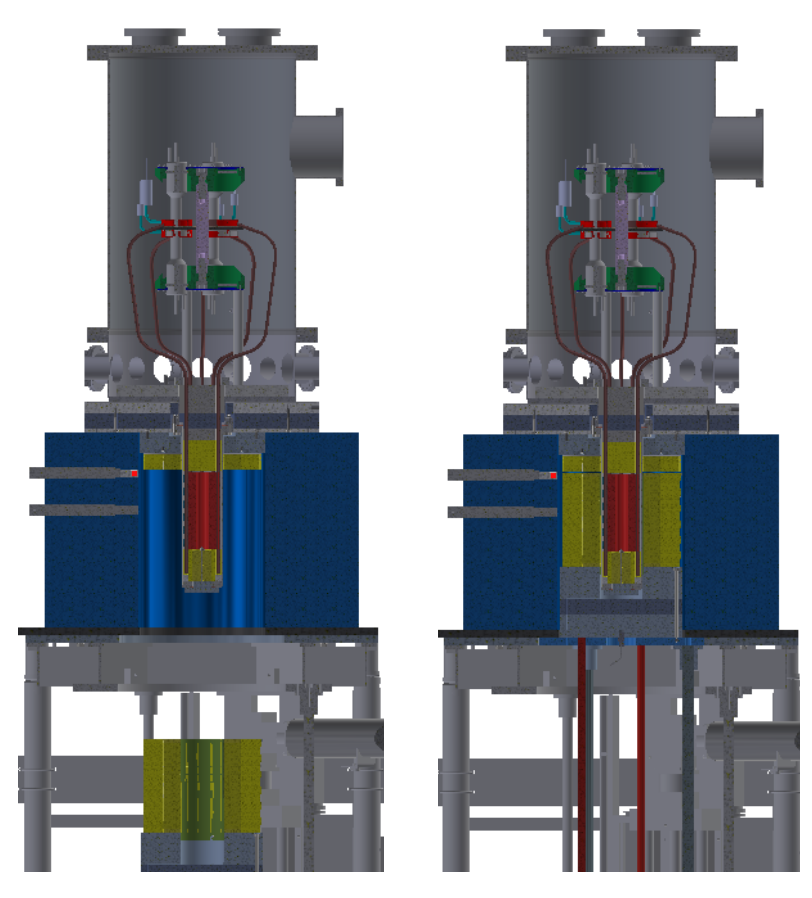

Figure 5. KRUSTY Test setup: Left, Beryllium Oxide radial reflector (lower yellow cylinder) shown prior to reactor startup; Right, radial reflector shown fully inserted around HEU core for full power operation.

\section{Full Power, High Temperature Testing}

The final KRUSTY test will be a full power run that will achieve the operating temperature of the reactor $(\sim 800 \mathrm{C}$ average core temperature). This test will require about $\$ 1.70$ in excess reactivity to achieve operating temperature. $\$ 2.20$ worth of excess reactivity will be loaded onto the machine in the form of more $\mathrm{BeO}$ radial reflector rings to cover any uncertainty in modeling or material measurements. The test will be run for approximately 28 hours. The test will begin like the previous low temperature runs, $\$ 0.15$ will be inserted at the start of the experiment and 
then bumped in regular intervals until the desired operating temperature is achieved. The system will be allowed to come to steady state for several hours. The first transient during this experiment will involve cutting the Stirling power removal by a factor of two and allowing the reactor to automatically adjust to the new power demand. After steady state is again achieved, the Stirlings will be brought back to maximum power removal allowing the reactor again to compensate and load follow back to the original power level. After running at steady state for several hours, the power removal on one Stirling engine will be eliminated to simulate a failed heat pipe or Stirling engine. The reactor will be allowed to adjust to this new condition and temperature measurements compared to modeling. Finally, after returning to full power steady state, all cooling to the reactor will be cut to simulate a full loss of cooling event. The reactor physics of this system is such that the temperature will rise to compensate and drop power to that level being dissipated by thermal radiation to the vacuum chamber walls. All runs will be compared to modeling of the full system for model validation.

\section{Expected Lessons Learned}

The KRUSTY test will be the first flight protypic nuclear test of a space reactor performed in decades. The results of the KRUSTY test will validate the computer models, methods, and data used in the reactor design. In addition, valuable experience in design, fabrication, startup, operation, transient behavior (load following based on reactor physics), and reactor shutdown will be obtained. The ultimate goal of the KRUSTY experiment is to show that a nuclear system can be designed, built, nuclear tested, and produce electricity via a power conversion system in a cost effective manner.

\section{SCIENCE MISSIONS}

\section{Titan Saturn System Mission}

In 2014, the NASA Glenn Research Center's Collaborative Modeling for Parametric Assessment of Space Systems (COMPASS) team completed a re-assessment study of the 2010 decadal survey Titan Saturn System Mission (TSSM) [12] using a uranium fueled $1 \mathrm{~kW}$ electric nuclear reactor in place of the original plutonium fueled $500 \mathrm{~W}$ stirling radioisotope system [9]. The TSSM goal was to explore Saturn's moon Titan by incorporating an orbiter, lander, and Montogolfier balloon for a total of over $100 \mathrm{~kg}$ of science payload.

The mission was designed using several propulsion technologies. After reaching geosynchronous transfer orbit from the launch stages, a solar electric propulsion stage would perform Earth and Venus flybys, with a jettison at the last Earth flyby, to obtain the necessary velocity for TransSaturn injection and the heliocentric cruise. Once at Saturn, a bipropellant chemical system would supply the deceleration and maneuvering required for Saturn orbit insertion where the two-year science mission would begin.

After 16 Titan flybys, release of the Montogolfier balloon and lander, 7 Enceladus flybys, Titan orbit insertion, and 200 Titan aerobrake maneuvers, a $1500 \mathrm{~km}$ orbit would finally be achieved for a 20 month science operation. The mission duration for the fission system totaled 15 years and 3 months with the reactor starting after the SEP jettison and the last earth flyby. Waiting to startup the reactor after the last earth flyby extends the fission power system life and makes it much safer than the radioisotope system with respect to a re-entry failure scenario.

The study concluded that the $1 \mathrm{kWe}$ fission reactor with Stirling conversion could complete the mission with the advantages of operating all the science instruments simultaneously and provide higher data rate communications with a smaller antenna. The main disadvantage was that the reactor powered spacecraft weighed $950 \mathrm{~kg}$ more than the ASRG version and took 2 more years to complete the Saturn mission.

The study team recommended that the reactor power system increase to $10 \mathrm{~kW}$ electric to incorporate a Nuclear Electric Propulsion (NEP) system in place of the Solar Electric Propulsion (SEP) stage, which could reduce the chemical propellant and eliminate aerobraking. These modifications would simplify the spacecraft and potentially reduce the total mass thus making the reactor powered system an attractive option. Figure 6 shows the TSSM spacecraft and fission power system.

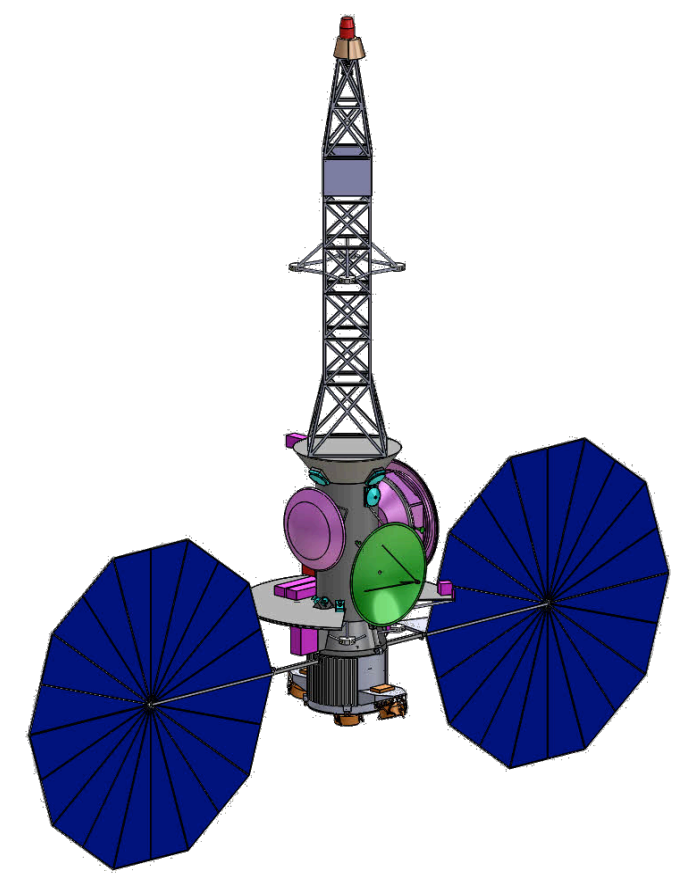

Figure 6. Titan Saturn System Mission spacecraft with attached $1 \mathrm{kWe}$ fission reactor 


\section{Chiron Orbiter}

2060 Chiron is a Centaur class object with a highly eccentric orbit, ranging from 8 to $19 \mathrm{AU}$, in the Saturn Uranus system with perihelion just inside Saturn's orbit and aphelion near that of Uranus's orbit. This minor planet differs from many other Centaur objects in that it exhibits comet like behavior that is visible near perihelion, making it an ideal candidate for primitive body research. In 2010, NASA's Goddard Space Flight Center (GSFC) Architecture Design Laboratory (ADL) and NASA Glenn's COMPASS team partnered together to study a Chiron Orbiter for the planetary science decadal survey steering committee and primitive bodies panel [1]. The purpose of the study was to evaluate power and propulsion strategies for putting $80 \mathrm{~kg}$ of science payload into a Chiron orbit at distances needed for 10 meter imaging resolution. Guidelines for the study included a ten year launch window between 2015-2025, New Frontier class cost cap of $800 \mathrm{M}$, and a limit of two ASRG power sources, which was later modified for additional ASRG units.

The study looked at several propulsion architectures for the mission including all chemical, chemical/SEP, 6 ASRG Radioisotope Electric Propulsion (REP), and 2 High Power (HP) ASRG REP. All the options used either the standard 134We ASRG or the conceptual 550W HP ASRG's for powering the spacecraft throughout the mission. It was concluded that the ASRG REP missions could meet all the science requirements and deliver the most science payload ( $72 \mathrm{~kg}$ for 6 standard ASRG, $76 \mathrm{~kg}$ for $2 \mathrm{HP}$ ASRG) to the Chiron orbit but could not fit within the $800 \mathrm{M}$ cost cap of a New Frontiers class mission.

Table 1. Chiron Orbiter mission: Comparison of Radioisotope Electric Propulsion (REP) and reactor powered Nuclear Electric Propulsion (NEP)

\begin{tabular}{|l|l|l|}
\hline Power System & REP & NEP \\
\hline Science and Trip Time & $\begin{array}{l}44 \mathrm{~kg} \mathrm{CBE} / 13 \mathrm{yr} \\
\text { trip / 1 yr science }\end{array}$ & $\begin{array}{l}44 \mathrm{~kg} \mathrm{CBE} / 13 \mathrm{yr} \\
\text { trip / 1 yr science }\end{array}$ \\
\hline Launcher & Atlas 551/Star 48V & Atlas 551 \\
\hline Launch Mass & $1300 \mathrm{~kg}$ & $4000 \mathrm{~kg}$ \\
\hline $\begin{array}{l}\text { Power: Level (EOL) / } \\
\text { Mass (alpha) }\end{array}$ & $\begin{array}{l}\text { Six 150W ASRG, } \\
900 \mathrm{We} / 189 \mathrm{~kg} \\
(4.7 \mathrm{We} / \mathrm{kg})\end{array}$ & $\begin{array}{l}\text { Single Fast Reactor, } \\
\text { Stirling Convertors } \\
8000 \mathrm{We} / 1142 \mathrm{~kg} \\
(7 \mathrm{We} / \mathrm{kg})\end{array}$ \\
\hline $\begin{array}{l}\text { Electric Propulsion } \\
\text { (Thrust/weight) }\end{array}$ & $\begin{array}{l}\text { Three 600 WHall, } \\
\sim 450 \mathrm{~kg} \mathrm{Xe}\end{array}$ & $\begin{array}{l}\text { Three 7000 W Ion, } \\
\sim 1600 \mathrm{~kg} \text { Xe }\end{array}$ \\
\hline $\begin{array}{l}\text { Size (Deployed / } \\
\text { Launch) }\end{array}$ & $\begin{array}{l}(2.2 \mathrm{~m} / 4 \mathrm{~m} \\
* \text { includes star48) }\end{array}$ & $(16 \mathrm{~m} / 7 \mathrm{~m})$ \\
\hline Nuclear material & $\sim 6 \mathrm{~kg} \mathrm{Pu238}$ & $\sim 75 \mathrm{~kg} \mathrm{93 \%} \mathrm{HEU}$ \\
\hline Radioactivity at launch & 91,840 Curies & $4.8 \mathrm{Curies}$ \\
\hline
\end{tabular}

In 2012 the COMPASS team re-opened the Chiron orbiter mission to add a fission powered nuclear electric propulsion system to the trade [6]. The objective of this study was to design an equivalent NEP version of the decadal survey REP baseline while using the same Atlas 551 launch vehicle by scaling the power of the reactor and electric thrusters to offset the extra mass. It was found that an $8 \mathrm{kWe}$ fission powered NEP system could deliver the required science payload within the 13 year time period using $7000 \mathrm{~W}$ ion engines. The increased capacity of the power and electric propulsion system allowed the NEP spacecraft to spiral out of Earth's gravity well on its own power without using the star 48 payload assist module.

At first glance (table 1), it appears that the NEP version is excessively heavy compared to its REP counterpart, but in fact, the heavier mass of the reactor was offset by using the higher power and higher Isp thrusters (and thus less propellant) than the REP version. Once in orbit around Chiron, all the reactor power could then be used for the science mission, which would allow the use of high power science instruments and high data rate communications. This benefit has not been studied by the science community but would likely provide a new evolution in science payloads and instruments. It should also be noted that REP and NEP are ENABLING for orbiting Chiron - no other way was found possible due to the lack of a substantial gravity well.

Launch safety is greatly reduced using the fission reactor because the radioactivity at launch is several orders of magnitude lower. Radioactivity comparisons of 91,840 curies for the radioisotope fuel to 5 curies of the highly enriched uranium fuel have a significant impact on launch safety analysis and overall public safety for fission powered nuclear missions.
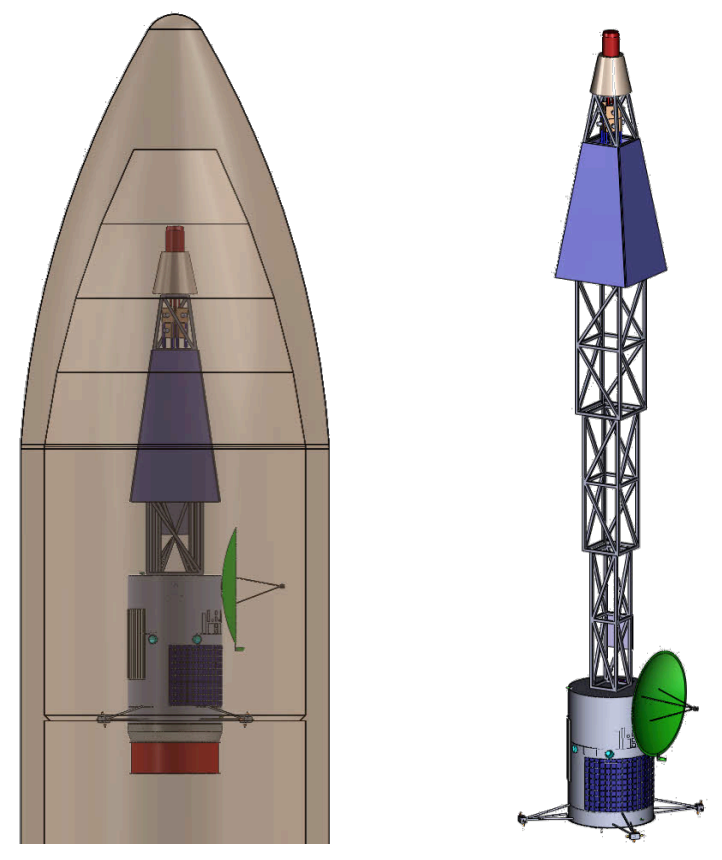

Figure 7. Chiron Orbiter spacecraft with 8kWe reactor and Nuclear Electric Propulsion (NEP) 


\section{Kuiper Belt Object Orbiter}

A similar design study from NASA GRC's COMPASS team and JPL's Team X was performed in 2011 to evaluate several REP spacecraft for a Neptune Flagship Orbiter, studied by JPL, and a Kuiper Belt Object Orbiter or KBOO studied by GRC. The KBOO spacecraft would launch in the 2030 timeframe and take 16 years of transit to support a 1year science mission. This flagship class mission sported conceptual designs of either eleven 420W advanced Radioisotope Thermoelectric Generators (RTG) or nine 550W advanced Stirling Radioisotope Generators (SRG).

The trans-Neptunian Kuiper Belt object 2001 XH255 was chosen as the target with a slight eccentricity of 0.07 with semi-major axis of $34.81 \mathrm{AU}$ and a perihelion of $32.28 \mathrm{AU}$. These bodies are assumed to be composed of frozen methane, water, and ammonia, which due to their vast distance from the sun, have presumably never been thawed. The original REP study proposed using a Delta IV Heavy with a Star $63 \mathrm{~F}$ upper stage to reach a C3 of $69.56 \mathrm{~km}^{2} / \mathrm{sec}^{2}$ with $3180 \mathrm{~kg}$ of launch mass. The electric propulsion system would operate continuously after launch until a Jupiter gravity assist in 2037, followed by a long coast period, and finally deceleration and orbit insertion 16 years later. Once in orbit at KBO 2001 XH255 the one year science mission would begin.

In 2012, the COMPASS team compared the REP system to an NEP system to once again understand the differences between the two power systems and determine if a higher power reactor could complete the mission at distances $>32$ AU $[4,5,8]$. With a similar design and results from the Chiron orbiter, it was found that an $8 \mathrm{kWe} \mathrm{NEP} \mathrm{system}$ could complete the same mission as the $4 \mathrm{kWe}$ REP system using the same launch vehicle, trip time, and science payload. Table 2 shows the results of the study with graphics in figure 8 .

The KBOO mission trade ended up with a better comparison between the REP and NEP systems with little difference in

Table 2. Kuiper Belt Object Orbiter (KBOO): Comparison of Radioisotope Electric Propulsion (REP) and Nuclear Electric Propulsion (NEP)

\begin{tabular}{|c|c|c|}
\hline Power System & REP & NEP \\
\hline Science and Trip Time & $\begin{array}{l}100 \mathrm{~kg} \mathrm{CBE} / 16 \mathrm{yr} \\
\text { trip / } 1 \text { yr science }\end{array}$ & $\begin{array}{l}100 \mathrm{~kg} \mathrm{CBE} / 16 \mathrm{yr} \text { trip / } 1 \\
\text { yr science }\end{array}$ \\
\hline Launcher & $\begin{array}{l}\text { Delta IV Heavy / } \\
\text { Star } 63\end{array}$ & Delta IV Heavy /Star 63 \\
\hline Launch Mass & $3100 \mathrm{~kg}$ & $3700 \mathrm{~kg}$ \\
\hline $\begin{array}{l}\text { Power: Level (EOL) / } \\
\text { Mass (alpha) }\end{array}$ & $\begin{array}{l}\text { Nine, 550W ASRG, } \\
4000 \mathrm{We} / 782 \mathrm{~kg}(5 \\
\mathrm{We} / \mathrm{kg})\end{array}$ & $\begin{array}{l}\text { Single Fast Reactor, Stirling } \\
\text { Convertors } 8000 \mathrm{We} / 1162 \\
\mathrm{~kg}(7 \mathrm{We} / \mathrm{kg})\end{array}$ \\
\hline $\begin{array}{l}\text { Electric Propulsion } \\
\text { (Thrust/weight) }\end{array}$ & $\begin{array}{l}1+13000 \mathrm{~W} \text { NEXT } \\
\text { Ion, } \sim 1200 \mathrm{~kg} \mathrm{Xe}\end{array}$ & $\begin{array}{l}1+17000 \mathrm{~W} \text { NEXT Ion, } \\
\text { Direct Drive, } \sim 1200 \mathrm{~kg} \text { Xe }\end{array}$ \\
\hline $\begin{array}{l}\text { Height (Deployed / } \\
\text { Launch) }\end{array}$ & $(6 \mathrm{~m} / 3 \mathrm{~m})$ & $(16 \mathrm{~m} / 7 \mathrm{~m})$ \\
\hline Nuclear material & $\sim 27 \mathrm{~kg} \mathrm{Pu} 238$ & $\sim 75 \mathrm{~kg} 93 \%$ enriched \\
\hline Radioactivity at launch & 413,260 Curies & 4.8 Curies \\
\hline
\end{tabular}

the overall mass. The fission system provides $100 \%$ more power then the radioisotope system with less than $20 \%$ extrta mass. This is due to the constant specific power ( 5 $\mathrm{We} / \mathrm{kg}$ ) of the REP system and the growing specific power $(7 \mathrm{We} / \mathrm{kg}$ ) of the NEP system as power levels increase. Another important feature is the increasing specific impulse of the higher power ion thrusters. This decreases the amount of zenon propellant needed for the NEP mission with both REP and NEP systems requiring $1200 \mathrm{~kg}$ of Xe. Radioactivity at launch provided another important parameter between the two systems with the REP system having 413,260 curies of radioactivity compared to the 5 curies associated with the NEP system, again favoring the safer uranium fuel for launch failure analysis scenarios.

According to the science mission studies, reactors could provide a higher power alternative to radioisotope systems, especially for missions requiring electric propulsion. The reactor technology could also enable new undefined missions, outside the capabilities of current power systems, with instruments that may not yet be developed. The overall goal of the Kilopower project is to design a highly reliable reactor with low re-occurring launch costs that will enable scientists the ability to propose missions with several kilowatts of power. Exploring a paradigm shift may be best answered with the following question: If a flight qualified $10 \mathrm{kWe}$ reactor were sitting on the shelf with a life expectancy of $20+$ years (after you start it), how might our science proposals and missions be different?
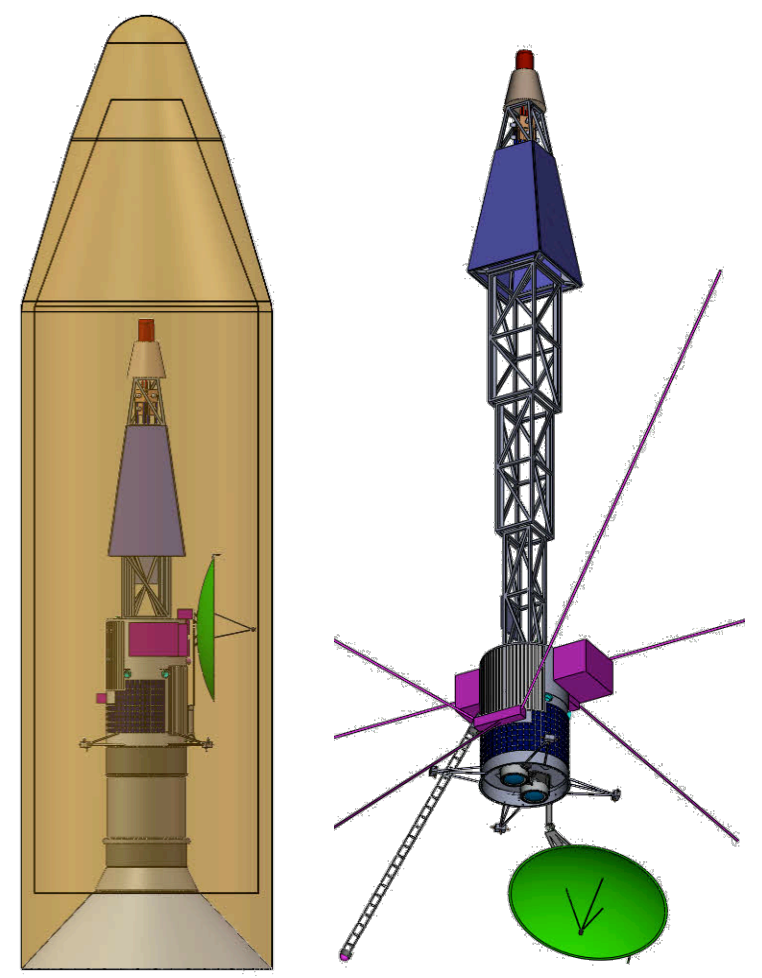

Figure 8. Kuiper Belt Object Orbiter spacecraft with 8kWe reactor and Nuclear Electric Propulsion (NEP) 


\section{Human Exploration Missions}

Mars

NASA and its commercial partners are focused on putting humans on Mars within the following two decades as the next great step in human exploration. The Mars Design Reference Architectures (DRA) [2] have base-lined fission power as the primary power system for surface operations and have recently established the $10 \mathrm{kWe}$ Kilopower reactor as the leading technology. There are two main phases of the Mars program that require new power system technology. The first phase requires a power system that will autonomously deploy and supply an In-Situ Resource Utilization (ISRU) plant. The ISRU plant will separate and cryogenically store the oxygen from the Martian atmosphere for Ascent vehicle propellant. The second phase requires the same autonomous power system to support the human crew that arrives after completion of the necessary propellant phase. The power requirements for both phases are directly linked to the number of astronauts arriving and the science missions involved during the stay. NASA DRA studies have settled on $40 \mathrm{kWe}$ as the required power level to support early Mars missions with a crew of 4-6 astronauts.

In 2016, the Human Exploration and Operations Mission Directorate (HEOMD) commissioned the COMPASS team to further evaluate the fission vs. solar trades for Mars [7]. The study looked at the requirements for both the ISRU and crewed phases of the mission with several different power architectures. Rucker et al reported the results [11] along with further evaluation on the subject. A brief summary is included here for discussion purposes.
Phase 1: ISRU Demonstrator

Launch Vehicle: Delta IV Heavy

Payload Mass to Mars Surface: $7500 \mathrm{~kg}$

Location: Jezero Crater, $18^{\circ} 51^{\prime} 18^{\prime \prime} \mathrm{N} 77^{\circ} 31^{\prime} 08^{\prime \prime} \mathrm{E}$

Propellant Production: $4400 \mathrm{~kg}$ of LOX (1/5 scale)

The study took 3 different approaches to the solar architecture design including 1A: daylight only operation at 1/5 production, 1B: around the clock operation at 1/5 production, and $1 \mathrm{C}$ : daylight only at $2 / 5$ production. All three designs used the ATK Ultraflex ${ }^{\text {TM }}$ arrays that were designed to operate at $120 \mathrm{~V}$ DC with a conversion efficiency of $33 \%$. The arrays were mounted on a gimbal that would track the sun and perform dust mitigation by sloping to 45 degrees. Array and battery sizing changed with architecture options with contingencies for a 120 day global dust storm and an average of $10 \mathrm{hrs} / \mathrm{Sol}$ of daylight. Lithium ion batteries were used for energy storage at 165 $\mathrm{W}-\mathrm{hr} / \mathrm{kg}$.

The fission option used a slightly oversized $10 \mathrm{kWe}$ Kilopower unit with a permanent radiator attached to the top of the lander. The reactor operated 24 hours a day at 6.5 $\mathrm{kWe}(65 \%$ capacity) with no interruptions or power loss from dust storms or landing locations. Power conversion was performed by (8) 1,250 We Stirling engines in the dual opposed configuration. Most lander subsystems were identical between the two power systems with some discrepancy in the thermal control systems. Comparison between the solar and fission power system ISRU demonstration mission are shown in Table 3 with conceptual drawings in Figures 9 and 10 .

Table 3. Solar vs. Fission for In-Situ Resource Utilization Demonstration Mission on Mars surface.

\begin{tabular}{|c|c|c|c|c|}
\hline Option & $\begin{array}{l}\text { Solar 1A: 1/5 } \\
\text { rate Daytime } \\
\text { Only }\end{array}$ & $\begin{array}{l}\text { Solar 1B: } 1 / 5 \text { rate } \\
\text { Around the Clock }\end{array}$ & $\begin{array}{l}\text { Solar 1C: } 2 / 5 \\
\text { Rate Daytime } \\
\text { Only }\end{array}$ & $\begin{array}{c}\text { Fission 2: 1/5 Rate } \\
\text { Around the Clock } \\
\text { Fission Power }\end{array}$ \\
\hline $\begin{array}{l}\text { Total Payload Mass } \\
\text { (including growth) }\end{array}$ & $1,128 \mathrm{~kg}$ & $2,425 \mathrm{~kg}$ & $1,531 \mathrm{~kg}$ & $2,751 \mathrm{~kg}$ \\
\hline Electrical Subsystem Mass & $455 \mathrm{~kg}$ & $1,733 \mathrm{~kg}$ & $639 \mathrm{~kg}$ & $1,804 \mathrm{~kg}$ \\
\hline ISRU Subsystem Mass & $192 \mathrm{~kg}$ & $192 \mathrm{~kg}$ & $335 \mathrm{~kg}$ & $192 \mathrm{~kg}$ \\
\hline Power & $\sim 8 \mathrm{~kW}$ Daylight & $\begin{array}{c}\sim 8 \mathrm{~kW} \text { Continuous } \\
\text { (with } 16 \mathrm{~kW} \text { of } \\
\text { arrays) }\end{array}$ & $\sim 16 \mathrm{~kW}$ Daylight & $\sim 7 \mathrm{~kW}$ Continuous \\
\hline Solar Arrays & $\begin{array}{c}4 \text { each } \times 5.6 \mathrm{~m} \\
\text { diameter }\end{array}$ & 4 each x $7.5 \mathrm{~m}$ dia. & $\begin{array}{c}4 \text { each } \times 7.5 \mathrm{~m} \\
\text { diameter }\end{array}$ & None \\
\hline Night Production? & No & Yes & No & Yes \\
\hline LOX Production & $4.5 \mathrm{~kg} / \mathrm{sol}$ & $10.8 \mathrm{~kg} / \mathrm{sol}$ & $9.0 \mathrm{~kg} / \mathrm{sol}$ & $10.8 \mathrm{~kg} / \mathrm{sol}$ \\
\hline $\begin{array}{l}\text { Time to Produce } 4,400 \mathrm{~kg} \\
\text { LOX, including } 120 \text {-Day } \\
\text { Dust Storm Outage }\end{array}$ & 1,098 sols & 527 sols & 609 sols & $407 \mathrm{sols}$ \\
\hline ISRU On/Off Cycles & 1,098 & $<5$ & 609 & $<5$ \\
\hline Radiation Tolerance & \multicolumn{3}{|c|}{100 kilorad (krad) electronics and ISRU } & $\begin{array}{c}300 \text { krad } \\
\text { electronics, } 10 \\
\text { Mega ad (Mrad) } \\
\text { ISRU }\end{array}$ \\
\hline
\end{tabular}


The ISRU 1/5 scale demonstrator favors solar in terms of mass but requires more time to produce the needed liquid oxygen. Option 1C offers the best balance between propellant production time and mass given the studies assumptions but does not adequately address the follow on energy storage requirements of a crewed mission and cycles on and off every day. For this reason, option 1B is a better technology demonstrator as it accomplishes both the ISRU and crew phase needs with minimal start/stop cycles. Trading option 1B with fission provides a more apples to apples comparison with minor differences in mass and propellant production time.

\section{Phase II: Crewed Mission}

Launch Vehicle: Space Launch System

Year: 2038; Crew: 4-6; Landed Mass: TBD

Locations: Jezero Crater, $18.9^{\circ} \mathrm{N} 77.5^{\circ} \mathrm{E}$

Columbus Crater $29.8^{\circ} \mathrm{S}, 166.1^{\circ} \mathrm{W}$

Propellant Production: $23000 \mathrm{~kg}$ of LOX

According to the NASA Design Reference Architecture 5.0 there will initially be three expeditions of 4-6 astronauts going to Mars for a stay of approximately 500 days for the conjuction class missions. Each expedition will land at a different location on Mars to adequately explore the diverse geological and environmental terrain. Each expedition will incorporate a pre-deploy mission architecture that allows a lower energy trajectory and larger payload masses with several key parts. First to arrive at the surface is the cargo landers, which house the autonomous power system, ISRU propellant production, and Mars Ascent Vehicle. The power system will initially be used to convert the Martian $\mathrm{CO}_{2}$ atmosphere into oxygen where it will then be cryogenically cooled and stored in the Mars Ascent Vehicle (MAV). After the required ascent propellant has been produced and stored in the MAV and the Mars orbiting habitat fully checked out, the crew will leave earth and rendezvous with the Mars Transfer Vehicle (MTV) in LEO and begin the 175-225 day fast-transit trajectory to Mars. After arriving in Mars orbit, the crew will rendezvous with the habitat and begin the entry, descent, and landing to the pre-deployed cargo landers to start their surface mission.

Rucker et al. [11] analyzed the ISRU COMPASS results to accommodate the crew phase logistics using the same technologies and general lander architectures to further evaluate the trade between solar and fission.

The results in table 4 give a brief summary of the power system comparison with insight into the differences between the crewed and un-crewed ISRU portions of the mission. The $50 \mathrm{kWe}$ fission system, $4+1$ spare $10 \mathrm{kWe}$ Kilopower units, is delivered on the first lander and provides all three expeditions the required power with a design life of 12 years. The reactors performance would not change based on global location or dust storms, and could be permanently attached to the lander or offloaded for strategic arrangement.

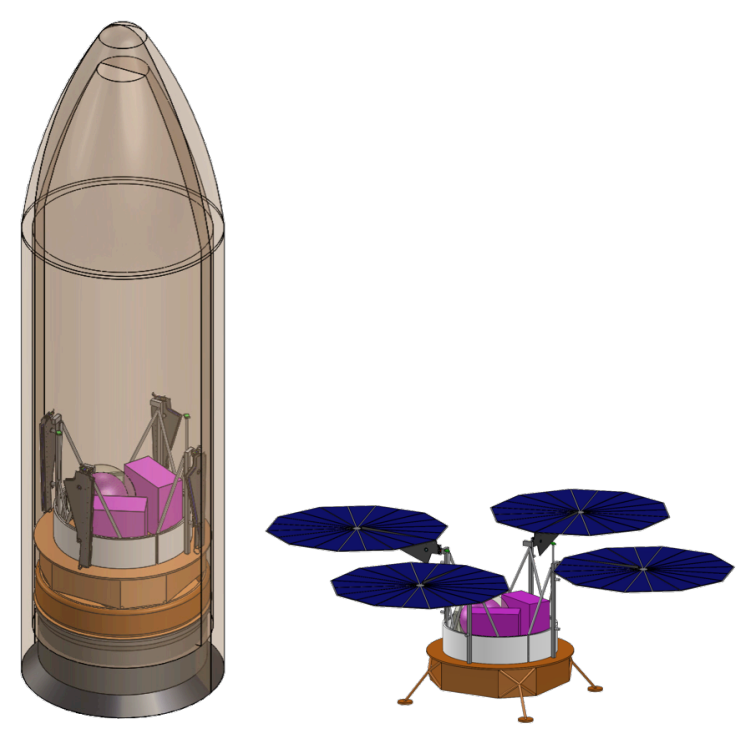

Figure 9. Mars ISRU solar powered lander concept in launch vehicle left, and deployed on Martian surface right
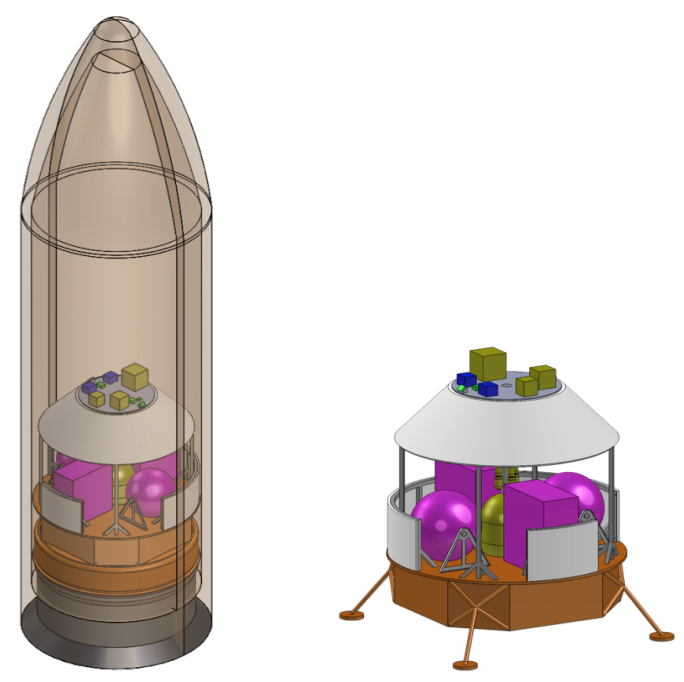

Figure 10. Mars ISRU fission powered lander concept in launch vehicle left, and deployed on Martian surface right

The solar architecture is analyzed at both the Jezero and Columbus crater sites to give insight into the locational constraints of the solar insolation on Mars. The main difference between the ISRU un-crewed mission and the crewed mission is the necessity for energy storage overnight and the additional requirements for crew keep alive power during the global dust storms. This energy storage and power management addition can be seen in the mass of the first lander of each expedition and in the subsequent landers, closely matching option 1B from the ISRU study.

These initial results show that the fission system for crewed expeditions is roughly half the mass of a comparable solar system, even at favorable solar latitudes. The rarely debated advantage of using fission surface power systems on Mars is their tolerance to dust storms and their ability to produce 
abundant power at any point on Mars. Another advantage that does not receive enough awareness is the potential for long power producing lifetimes beyond mission requirements. The Kilopower reactor's thermal output in relation to the core's total fissionable energy is small, which reduces the fuel burnup significantly. With controlled reactivity insertion throughout the lifetime of the reactor it is possible to achieve full power production for several decades. Although this advantage is attractive it cannot be easily tested in ground demonstrations and will require an extended space mission to fully prove. The disadvantage of fission is the produced radiation, requiring shielding to protect equipment and crew. The mission architectures will likely have astronaut keep out zones and radiation safety protocols that would not be required with solar systems. For non-human rated systems, such as the ISRU demo or other mechanical/electrical systems, radiation hardened components will greatly reduced the amount of shielding required and thus leading to mass benefits.

The advantages of solar are their simplicity, redundancy, and flight heritage that have been proven with many successful missions. The challenges for solar missions to Mars have remained numerous regarding dust accumulation on solar panels, limited solar insolation from dust storms, and available sunlight at northern and southern latitudes. These very reasons supported decisions to move away from solar powered rovers such as Spirit and Opportunity and replace them with a nuclear powered Multi-Mission Radioisotope Thermoelectric Generators (MMRTG) as seen on the Mars Science Laboratory.

Table 4. Solar vs. Fission mass comparison for the three expedition Astronaut crew phase of a Mars surface mission.

\begin{tabular}{|c|c|c|c|}
\hline \multirow{3}{*}{$\begin{array}{c}\text { Crew } \\
\text { Expedition }\end{array}$} & \multicolumn{3}{|c|}{ Power Generation/Storage Mass (kg) } \\
\hline & \multirow{2}{*}{$\begin{array}{l}\text { Fission } \\
\text { Power }\end{array}$} & \multicolumn{2}{|c|}{ Solar Power } \\
\hline & & $\begin{array}{l}\text { Jezero } \\
\text { Crater }\end{array}$ & $\begin{array}{c}\text { Columbus } \\
\text { Crater }\end{array}$ \\
\hline Expedition 1 & 9,154 & 11,713 & 12,679 \\
\hline Lander 1 & 9,154 & 5,611 & 5,909 \\
\hline Lander 2 & 0 & 2,034 & $* 2,704$ \\
\hline Lander 3 & 0 & 2,034 & 2,033 \\
\hline Lander 4 & 0 & 2,034 & 2,033 \\
\hline Expedition 2 & $\mathbf{0}$ & 6,102 & 6,770 \\
\hline Lander 1 & 0 & 2,034 & $* 2,704$ \\
\hline Lander 2 & 0 & 2,034 & 2,033 \\
\hline Lander 3 & 0 & 2,034 & 2,033 \\
\hline Expedition 3 & $\mathbf{0}$ & $\mathbf{0}$ & $\mathbf{0}$ \\
\hline Lander 1 & 0 & 0 & 0 \\
\hline Lander 2 & 0 & 0 & 0 \\
\hline Lander 3 & 0 & 0 & 0 \\
\hline $\begin{array}{c}\text { Three Mission } \\
\text { Total (kg) }\end{array}$ & 9,154 & 17,815 & 19,449 \\
\hline
\end{tabular}

Presumably, the ISRU demonstration slated to launch in the mid 2020's will determine the outcome of solar vs. nuclear for near term Mars missions. Regardless of the outcome, it is likely that both technologies will play a significant role in the Mars missions to come with more solar deployments in the equatorial regions and nuclear expeditions in the polar regions. A combination of solar and fission will only add redundancy to the Mars missions and enable all possible expeditions.

\section{SUMMARY}

Science and human missions using fission power sources have been independently studied with positive results. Although scientists have been stifled about proposing kilowatt class missions due to their non-existence over the past 50 years, it is encouraging that the paradigm could be changing with the technology advancement of the Kilopower reactor. Specific interests in fission based nuclear electric propulsion have been acknowledged knowing that the power requirements are realistically outpacing the radioisotope fuel availability and production. Two decadal survey missions using NEP systems were studied by the COMPASS team with the goal of delivering an orbiter around the centaur class object Chiron and a Kuiper Belt Object (KBO). Both studies were able to close the mission objectives with a $7-10 \mathrm{kWe}$ Kilopower reactor. These missions are well fitted for space reactors as the power levels are easily achieved with the abundance of Uranium fuel. It's estimated that many of the decadal survey missions could be achieved and possibly enhanced with nuclear reactors and will be further studied as the Kilopower technology is further developed.

The human exploration of Mars will undoubtedly be the greatest achievement of the century and is quickly becoming a near term reality. Many of the necessary technologies are already being developed and tested with no exception to nuclear power. The independent studies cited herein have pointed out some of the advantages of nuclear surface power and how the Kilopower reactor can reduce several risks associated with the Martian environment that has been relentless to the solar powered missions. The study concluded that both the ISRU and crew phases of the early Mars missions were easily achieved with several $10 \mathrm{kWe}$ Kilopower reactors. The Kilopower based system won the mass and power trades for the crewed missions by a factor or two even at solar favorable sites, which provides additional support for nuclear systems when moving further from the equator.

The Kilopower reactor is well on its way to surpassing the technology barriers that have existed over the last half century. With a successful completion of the full scale nuclear ground test nicknamed KRUSTY (Kilopower Reactor Using Stirling TechnologY), the technical and programmatic risks for space nuclear power will be significantly reduced in proving that nuclear technologies can be affordably developed and tested. The neutronic 
verification at full power and temperature for extended periods will provide the needed data for flight system development in the post KRUSTY years. Increased necessity and advocacy for space nuclear power is expected as we expand our presence in the solar system and explore new worlds. It is more a matter of the perseverance required to fully develop a flight-qualified reactor and begin using it. 


\section{REFERENCES}

[1] Buie, Marc, and Joe Ververka. Chiron Orbiter Mission. SWRI, Cornell University, NASA, 2010.

[2] Drake, Bret G., and Kevin D. Watts. Human Exploration of Mars Design Reference Arcitecture 5.0. NASA SP-2009566, 2009.

[3] Gibson, Marc A., Max Briggs et al. "Heat Powered Stirling Conversion for the Demonstration Using Flattop Fission (DUFF) Test." Nuclear and Emerging Technologies for Space. Albuquerque: NETS paper 6812, 2013.

[4] Mason, Lee, Marc A. Gibson, and David I Poston. "Kilowatt-Class Fission Power Systems for Science and Human Precursor Missions." Nuclear and Emerging Technologies for Space. Albuquerque: NASA TM-2013216541, 2013.

[5] Oleson, Steven R., Melissa L. McGuire et al. "Kuiper Belt Object Orbiter Using Advanced Radioisotope Power Sources and Electric Propulsion." Proceedings of Nuclear and Emerging Technologies for Space. Albuquerque, 2011.

[6] Oleson, Steven R., and NASA Glenn COMPASS team. "Chiron Orbiter using Nuclear Electric Propulsion." NASA (internal report), 2012.

[7] Oleson, Steven R., and NASA Glenn COMPASS team. "Mars ISRU Power System Demonstrator." NASA (internal report), 2016.

[8] Oleson, Steven R., and NASA Glenn COMPASS team. "Radioisotope-Fission Breakpoint Design Reference Mission 1 (Flagship Class) Kuiper Belt Orbiter." NASA (internal report), 2012.

[9] Oleson, Steven R., and NASA Glenn COMPASS team. Titan Saturn System Mission with Stirling and Thermal Electric Fission Power Systems. NASA CD-2014-109, 2014.

[10] Poston, David I., and Patrick R. McClure. "The DUFF Experiment-What was Learned." Nuclear and Emerging Technologies for Space. Albuquerque: NETS paper 6967, 2013.

[11] Rucker, Michelle A., and Steven R. Oleson. "Solar Versus Fission Surface Power for Mars." SPACE Conferences and Expositions. Long Beach: AIAA 20165452, 2016.

[12] Spencer, John, Niebur, Curt. "Planetary Science Decadal Survey Titan Saturn System Mission." NASA Mission Concept Study, 2010.

\section{BIOGRAPHY}

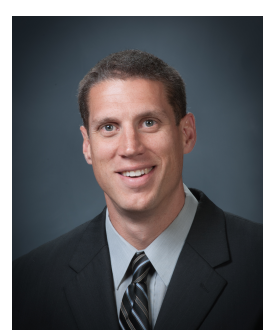

Marc Gibson is the lead engineer for NASA's nuclear systems Kilopower project tasked with advancing the technology readiness of fission power systems for space. Marc started his career at NASA in 2007 after working in the private sector for ten years as chief engineer for numerous commercial and government research projects. Since being at NASA, Marc has been responsible for the engineering and development of nuclear systems for in-space and planetary surface power in support of the Space Technology Mission Directorate. Marc received a BS in Mechanical Engineering from the University of Akron and a MS in Aerospace Engineering from the Case Western Reserve University.

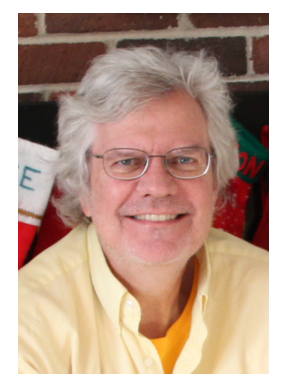

DAVID POSTON is the leader of the Compact Fission Reactor Design Team at Los Alamos National Laboratory. This team is responsible for the design and development of nuclear fission reactors for civilian, NASA, and defense applications in space. Dr. Poston's 25 years of space reactor experience has been primarily been focused on near-term concepts for solar system exploration (including designs for missions to the Moon, Mars, Jupiter and Neptune). Prior to his experience at Los Alamos, Dr. Poston worked at GE Nuclear Energy for 4 years on advanced reactor design. Dr. Poston received a BS in Mechanical Engineering the University of Michigan, an MS in Mechanical Engineering from Stanford University, an MS in Nuclear Engineering from the University of California at Berkeley, and a PhD in Nuclear Engineering from the University of Michigan.

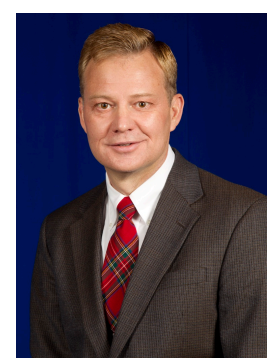

PATRICK MCCLURE is the project manager for small nuclear reactor projects at LANL. He is the former line manager for the Nuclear System Design and Analysis Group. He has been at LANL for 22 years performing nuclear design for reactor systems and safety analysis for the light water reactors with an emphasis on severe nuclear accidents like Three Mile Island and Fukushima. Mr. McClure has a B.S. from the University of Oklahoma and a M.S. from the University of New Mexico. 


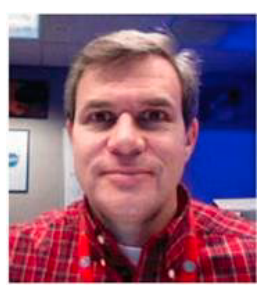

Steve Oleson leads the COMPASS

Concurrent Engineering Team, which is responsible for developing conceptual space system designs. Begun in 2006, the COMPASS Team has designed over 100 spacecraft concepts including the SCAN Communications Testbed flown on the International Space Station and the Asteroid Redirect 17 Mission, which is currently under development. The COMPASS team recently received a NASA Group Achievement Award for its efforts. Steve has twenty seven years of experience in conceptual engineering of space systems, technology development and test, and mission analysis. He has published over 100 papers on spacecraft concepts and mission design. He has an MS. in Astronautical Engineering from the Air Force Institute of Technology, and a B.S. in Mechanical Engineering from the Ohio Northern University. He was recently awarded the NASA Outstanding Leadership Medal for his leadership of COMPASS. 